\title{
Detection and Classification of Individual Airborne Microparticles using Laser Ablation Mass Spectroscopy and Multivariate Analysis
}

\section{MEOEIVED \\ MAY 201939 \\ OSTI}

Eric P. Parker, Stephen E. Rosenthal, Michael W. Trahan, and John S. Wagner Sandia National Laboratory

Department 15334: Laser and Computational Initiatives

William B. Whitten, Rainer A. Gieray, Peter T. A. Reilly, Alexandru Lazar, And J. Michael Ramsey

Oak Ridge National Laboratory

Laser Spectroscopy and Microinstrumentation Group 


\section{DISCLAIMER}

This report was prepared as an account of work sponsored by an agency of the United States Government. Neither the United States Government nor any agency thereof, nor any of their employees, make any warranty, express or implied, or assumes any legal liability or responsibility for the accuracy, completeness, or usefulness of any information, apparatus, product, or process disclosed, or represents that its use would not infringe privately owned rights. Reference herein to any specific commercial product, process, or service by trade name, trademark, manufacturer, or otherwise does not necessarily constitute or imply its endorsement, recommendation, or favoring by the United States Government or any agency thereof. The views and opinions of authors expressed herein do not necessarily state or reflect those of the United States Government or any agency thereof. 


\section{DISCLAIMER}

Portions of this document may be illegible in electronic image products. Images are produced from the best available original document. 


\begin{abstract}
We are developing a method for the real-time analysis of airborne microparticles based on laser ablation mass spectroscopy. Airborne particles enter an ion trap mass spectrometer through a differentially-pumped inlet, are detected by light scattered from two $\mathrm{CW}$ laser beams, and sampled by a $10 \mathrm{~ns}$ excimer laser pulse at $308 \mathrm{~nm}$ as they pass through the center of the ion trap electrodes. After the laser pulse, the stored ions are separated by conventional ion trap methods.

In this work thousands of positive and negative ion spectra were collected for eighteen different species: six bacteria, six pollen, and six particulate samples. The data were then averaged and analyzed using the Multivariate Patch Algorithm (MPA), a variant of traditional multivariate analysis. The MPA correctly identified all of the positive ion spectra and 17 of the 18 negative ion spectra. In addition, when the average positive and negative spectra were combined the MPA correctly identified all 18 species. Finally, the MPA is also able to identify the components of computer synthesized mixtures of the samples studied
\end{abstract}




\section{Introduction}

There is an increasing awareness that exposure of the general population to biological pathogens is becoming more likely, whether by overt or accidental releases. There are a number of very effective analytical techniques to identify pathogenic organisms [1-16]. These include DNA identification and immunoassay. However, for several reasons, these methods are not attractive for continuous monitoring of the environment for the presence of undesirable species. They are generally labor intensive and are batch processes with sample requirements of $10^{2}$ to $10^{6}$ cells with several minutes required for a determination, and species-specific reagents that must be refrigerated are required. One alternate approach is to employ conventional methods of chemical analysis to identify biomarkers that can be used to identify or classify the suspected pathogen. Various mass spectrometric methods are prominent in this effort, including pyrolysis and fast atom bombardment for fatty acid analysis, and matrix assisted laser desorption/ionization (MALDI) and electrospray mass spectrometric characterization of species-specific proteins. These methods are also in general batch processes. A hybrid approach to pathogen identification is to employ a less specific real-time analytical monitoring technique to detect substantial changes in the background concentration of environmental organisms and thus indicate that a more selective assay should be initiated. Early methods relied on excursions in total airborne particle concentration, sometimes with size selection, to trigger an analysis. More recently, instruments that measure the fluorescence intensity or fluorescence spectrum have been developed for enhanced discrimination of biological particles. The purpose of this paper is to describe experiments using laser ablation mass spectrometry of individual particles together with computer-based particle classification to detect airborne bacteria in real time.

\section{Multivariate Analysis}

The multivariate analysis presented in this work was performed using the Multivariate Patch Algorithm (MPA) developed at Sandia National Laboratories, which computes the concentrations of chemicals in a mixture by making reference to a library of premeasured spectral signatures or "knowns". The MPA is a variant of multivariate analysis that was originally developed to minimize the residuals of organized pixel sets or "patches". This process has been described in depth elsewhere $[17,18]$, so only a brief description will be given here. The MPA is conceptually similar to a classical least-squares fit, due to the fact that it chooses the concentrations of specified known spectra to minimize the residuals between the unknown mixture and the fitted solution. The patch algorithm extends this approach by minimizing the residuals on pixel sets, which collectively contain the most important features in a particular chemical spectrum. Mathematically, the patch algorithm computes the residuals between the mixture and a hypothetical solution for all pixels in a patch, then minimizes this residual, or a function of this residual for each patch. After the concentrations are estimated the algorithm then computes an uncertainty estimate derived from the first three terms of the Taylor series expansion of the rate of change of concentration from the unknown mixture, the known chemical database and the mixture-known (cross product) uncertainty. The uncertainty estimates are not shown in the results presented here, as we do not have uncertainty estimates for the data used to produce the known and unknown spectra. 


\section{Methods}

\section{Mass Spectroscopy}

The methods used to collect the data have been described in depth previously [19]. In brief, airborne particles pass through a collimating inlet system consisting of a capillary and two skimmers which separate differentially-pumped chambers before entering the vacuum chamber that houses the ion trap electrodes. The incoming particles are sensed as they pass through two continuous-wavelength laser beams prior to entering the vacuum chamber. A trigger pulse is generated which then fires an excimer laser at $308 \mathrm{~nm}$, striking the detected particles as they pass through the center of the ion trap electrodes and breaking each particle into a random distribution of ionic fragments. A mass spectrum of either positive or negative ions is acquired for each particle.

In this work eighteen different samples were studied: six bacteria, six pollen, and six particulate samples. The species studied are listed in Table One. Both positive and negative ion data were collected for each species. A dataset for each species studied (either positive or negative) consists of hundreds of mass spectra, each spectrum being generated from a single microparticle. We obtained two complete datasets for each of the bacteria and particulates studied, but only one dataset for each of the pollens studied. Accordingly, we decided to evaluate two complete sets of results, the first set using the first dataset for each bacterium and particle and the second set using the second dataset for each bacterium and particle. Both sets of results use the same dataset for each pollen sample.

\begin{tabular}{|c|c|c|}
\hline & Table One: Samples Studied \\
\hline Bacteria & Pollen & Particulate Matter \\
\hline $\begin{array}{c}\text { Azotobacter vinelandii } \\
\text { (Avin) }\end{array}$ & $\begin{array}{c}\text { Ambrosia trifida } \\
\text { (Ambtri) }\end{array}$ & $\begin{array}{c}\text { NIST 1645 River Sediment } \\
\text { (1645) }\end{array}$ \\
\hline $\begin{array}{c}\text { Bacillus subtilis } \\
\text { (Bsubt) }\end{array}$ & $\begin{array}{c}\text { Artemisia tridentata } \\
\text { (Arttr) }\end{array}$ & $\begin{array}{c}\text { NIST 4350b River Sediment } \\
\text { (4350b) }\end{array}$ \\
\hline $\begin{array}{c}\text { Escherichia coli } \\
\text { (Ecoli) }\end{array}$ & $\begin{array}{c}\text { Betula alba } \\
\text { (Betalb) }\end{array}$ & $\begin{array}{c}\text { NIST 8407 River Sediment } \\
\text { (8407) }\end{array}$ \\
\hline $\begin{array}{c}\text { Enterobacter aerogenes } \\
\text { (Enter) }\end{array}$ & $\begin{array}{c}\text { Dactylis glomerata } \\
\text { (Dacglo) }\end{array}$ & $\begin{array}{c}\text { NIST 2710 Montana Soil } \\
\text { (Mont) }\end{array}$ \\
\hline $\begin{array}{c}\text { Miccrococcus lysodeikticus } \\
\text { (Micro) }\end{array}$ & $\begin{array}{c}\text { Juglans nigra } \\
\text { (Juglan) }\end{array}$ & $\begin{array}{c}\text { NIST Peruvian Soil } \\
\text { (Peru) }\end{array}$ \\
\hline $\begin{array}{c}\text { Bacillus globigii spores } \\
\text { (Spore) }\end{array}$ & Agrostis alba \\
(Grass) & NIST 1648 Urban Particulate \\
& Matter \\
& & (Urbanp) \\
\hline
\end{tabular}




\begin{tabular}{|c|c|c|c|c|c|c|c|c|}
\hline \multicolumn{9}{|c|}{ Table Two: MPA Results } \\
\hline \multirow{3}{*}{ Species } & $\begin{array}{c}\text { Negative Ion } \\
\text { Spectra }\end{array}$ & & $\begin{array}{c}\text { Positive Ion } \\
\text { Spectra }\end{array}$ & & \multicolumn{2}{c|}{$\begin{array}{c}\text { Combined } \\
\text { Spectra }\end{array}$} \\
\cline { 2 - 9 } & Set 1 & Set 2 & & Set 1 & Set 2 & & Set 1 & Set 2 \\
\hline Avin & A & A & & A & A & & A & A \\
\hline Bsubt & B & B & & C & B & & B & C \\
\hline Ecoli & A & A & & A & A & & A & A \\
\hline Enter & B & B & & A & A & & A & A \\
\hline Micro & D & F & & A & A & & A & A \\
\hline Spore & B & B & & A & A & & A & A \\
\hline & & & & & & & & \\
\hline Ambtri & B & A & & A & A & & A & A \\
\hline Arttri & B & A & & A & A & & A & A \\
\hline Betalb & B & B & & A & A & & A & A \\
\hline Dacglo & A & B & & A & A & & A & A \\
\hline Juglan & C & C & & A & A & & A & A \\
\hline Grass & A & A & & A & A & & A & A \\
\hline & & & & & & & & \\
\hline 1645 & A & A & & A & A & & A & A \\
\hline $4350 b$ & C & A & & A & B & & A & B \\
\hline 8407 & B & A & & A & B & & A & A \\
\hline Mont & C & A & & A & A & & A & A \\
\hline Peru & A & B & & B & A & & A & A \\
\hline Urbanp & C & B & & B & A & & A & A \\
\hline
\end{tabular}

Column headings:

Set 1: The first dataset is split in halves, with the average of the first half being used as the known and the average of the second half being used as the unknown.

Set 2: The second dataset is split in halves, with the average of the first half being used as the known and the average of the second half being used as the unknown.

The criteria used to obtain the results in Table Two are given below. In these criteria the peak belonging the known spectrum which corresponds to the unknown being analyzed is referred to as the species peak.

Criteria for evaluating MPA results

A: all other peaks have a relative height $<0.15$ of the height of the species peak.

B: all other peaks have a relative height $<0.33$.

C: all other peaks have a relative height $<0.67$.

D: all other peaks have a relative height $<1.0$.

F: the species peak is not the highest positive peak. 
After examining both sets of results in Table Two we see that the majority of species are correctly identified. A grade of D or better represents a correct identification, while a grade of $\mathrm{C}$ or better represents a satisfactory identification. In the first set of results MPA correctly identifies all 18 negative ion spectra, all 18 positive ion spectra, and all 18 combined spectra. In the second set of results MPA correctly identifies 17 of 18 negative ion spectra, all 18 positive ion spectra, and all 18 combined spectra. The results obtained when the positive and negative spectra are combined are even better. Specific examples are both sets of combined spectra for Micro and the combined spectra for Urbanp from set 1 . In the case of Micro, combining the negative ion result ( $D$ for set $1, F$ for set 2 ) and the positive ion result ( $A$ in both cases) yields a combined spectrum which is rated an A in both cases. Similarly, for the Urbanp soil sample the individual polarities rate a $\mathrm{C}$ (negative) and a $\mathrm{B}$ (positive), while the combined result rates an $\mathrm{A}$.

Examining Micro, the one negative ion case where the results were either unsatisfactory or wrong, we find that the major part of the interference is due to another bacterium. The interfering species and their peak heights relative to that of the Micro peak are listed in table Three.

Table Three: Micro Negative Ion Results -- Interfering Species and Relative Peak Heights

\begin{tabular}{|c|c|c|c|c|}
\hline Set 1 & Bsubt (0.8860) & Enter (0.9079) & Spore (0.9956) & Peru (0.3991) \\
\hline Set 2 & Bsubt (1.3390) & Enter (0.9718) & Spore (1.3390) & $4350 \mathrm{~b}(0.2373)$ \\
\hline
\end{tabular}

The MPA uses a combination of the specified known spectra to describe an unknown spectrum and then lists the concentration of each known used in producing the final result. Ideally, the spectrum from a single type of particle should contain $100 \%$ of the representative spectrum and $0 \%$ of all the others. Since the single particle laser ablation mass spectra vary widely from particle to particle, however, even the averages over several hundred spectra differ slightly from another part of the set. Thus, even in the best cases the MPA usually determines that an average of spectra from one type of particle contains some concentration of the other particles in the library. The fact that MPA solutions are a linear combination of components is also why there are usually (if not always) negative peaks in a solution.

If we examine the common features (the interference's) in the MPA results further we find some interesting trends. For instance, in both sets of results the negative ion spectra show a number of common features between bacteria and soil samples (Figure 3A). In contrast, there is only one instance of a common feature between either a bacterium or particle and a pollen (Figure 3B). Even in the case of the set 2 result for Bsubt, though, the common feature with Dacglo is comparatively weak. In fact, even the individual pollens don't seem to have features in common - rather, they share features with the bacteria and particulate samples. Another interesting note is the lack of common features between the positive spectra of the pollens and any other species (Figure 3, C\&D). This simply emphasizes that the pollens are consistently among the best identified of the species studied. 


\section{Conclusions}

We have shown that the MPA is able to identify single component unknowns for both ionic polarities, yielding satisfactory identifications in all but one case. Furthermore, MPA is able to identify the components of computer synthesized mixtures. In fact, MPA deals well not only with mixtures whose components are distinct, but also with mixtures whose component spectra are very similar (Figure 4$)$.

Additionally, the MPA analysis demonstrates that combining the positive and negative ion spectra yields notably improved results. As Set 1 shows, when both positive and negative ion spectra are combined the MPA can correctly distinguish each of the 18 particle types from the others with a signal to noise ratio greater than 3 , i.e., no other particle appears to be present in the average at more than $33 \%$. This leads us to conclude that the ability to collect all the ions (both positive and negative) produced by the laser ablation of a microparticle will lead to improved identification of its components.

The MPA is only one member of a suite of analysis programs developed at Sandia and used to analyze the mass spectra studied here. Other approaches include using a Genetic Algorithm (GA) to train a population of Neural Nets to distinguish between mass spectra from bacteria and mass spectra from non-bacteria [20]. In the future we intend to add data on the size of microparticles to the database, transforming it from a 1-D to a 2-D database. This will allow us to use a GA to optimize the patch used by the MPA, which should improve our results even further. Ultimately, combining improvements in the database and the analysis software will make it easier to do real-time analysis of airborne microparticles.

\section{Acknowledgments}

The authors would like to thank Ms. Agnes Akinyemi of Edgewood Research Development and Engineering Center for preparing the sample of Bacillus globigii spores.

This work was sponsored by the U.S. Department of Energy, Office of Research and Development.

Sandia is a multiprogram laboratory operated by Sandia Corporation, a Lockheed Martin Company, for the United States Department of Energy under Contract DE-AC04-94AL85000.

Oak Ridge National Laboratory is operated by Lockheed Martin Energy Research Corporation for the United States Department of Energy under Contract DE-AC05-96OR22464. 


\section{References}

1) R.G. Pinnick, S.C. Hill, P. Nachman, G. Videen, G. Chen, R.K. Chang, "Aerosol Fluorescence-Spectrum Analyzer For Rapid Measurement Of Single Micrometer-Sized Airborne Biological Particles", Aerosol Science And Technology 28, 95-104 (1998).

2) S.H. Wood, K.A. Prather, "Time-Of-Flight Mass-Spectrometry Methods For Real-Time Analysis Of Individual Aerosol Particles", Trends in Analytical Chemistry 17, 346-356 (1998).

3) P.C. Gray, I.R. Shokair, S.E. Rosenthal, G.C. Tisone, J.S. Wagner, L.D. Rigdon, G.R. Siraguse, R.J. Heinen, "Distinguishability of biological material by use of ultraviolet multispectral fluorescence", Applied Optics 37, 6037-6041 (1998).

4) D.S. Gross, K.A. Prather, "Real-Time Analysis Of Individual Ambient Aerosol-Particles", Abstracts Of Papers Of The American Chemical Society 214, pp.7 (1997).

5) J. Lacey, "Sampling And Rapid Assay Of Bioaerosols: Proceeding Of A Joint Meeting Of The British-Aerobiology-Federation And The Aerosol Society", Journal of Aerosol Science 28, 345348 (1997).

6) P. Nachman, G. Chen, R. Pinnick, S. Hill, K. Chang, M. Mayo, and G. Fernandez, "Conditional-sampling spectrograph detection system for fluorescence measurements of individual airbörne biological particles”, Applied Optics 35, 1069-1076 (1996).

7) C.A. Noble, K.A. Prather, "Real-time measurement of correlated size and composition profiles of individual atmospheric aerosol particles", Environmental Science And Technology 30, $2667-$ 2680 (1996).

8) G. Chen, P. Nachman, R.G. Pinnick, S.C. Hill, R.K. Chang, "Conditional-firing aerosolfluorescence spectrum analyzer for individual airborne particles with pulsed 266-nm laser excitation", Optics Letters 21, 1307-1309 (1996).

9) B. Spengler, K.P. Hinz, R. Kaufmann, "Airborne Particle Analysis", Science 274, pp.1996 (1996).

10) M.V. Johnson, A.S. Wexler, "Analysis of individual aerosol particles", Analytical Chemistry 67, 721A-726A (1995).

11) S.C. Hill, R.G. Pinnick, G. Chen, R.K. Chang, M.W. Mayo, and G.L. Fernandez, "Aerosolfluorescence spectrum analyzer: real-time measurement of emission spectra of airborne biological particles", Applied Optics 34, 7149-7155 (1995).

12) K.R. Spurny, "On the chemical detection of bioaerosols", Journal of Aerosol Science 25, 1533-1547 (1994).

13) W.D. Griffiths, G.A.L. DeCosemo, "The assessment of bioaerosols: a critical review", Journal of Aerosol Science 25, 1425-1458 (1994).

14) D.C. White, D.B. Ringelberg, D.B. Hendrick, D.E. Nivens, "Rapid identification of microbes from clinical and environmental matrices", Mass spectrometry for the Characterization of 
Microorganisms, C. Fenselau Ed., ACS Symposium Series 5411, American Chemical Society, Washington DC, 1994.

15) M.P. Sinha, "Analysis of individual biological particles in air", Rapid Detection and Identification of Microorganisms, W. H. Nelson Ed., VCH Pubilishers, Deerfield beach, FL, 1985, pp. 165-192.

16) M.P. Sinha, R.M. Platz, V.L. Viker, S.K. Friedlander, "Anaalysis of individual biological particles by mass spectrometry", International Journal Of Masss Spectrometry Ion Processes 57, 125-133 (1984).

17) M.W. Trahan, J.S. Wagner, I.R. Shokair, G.C. Tisone, P.C.. Gray, "The Use of Intelligent Algorithms in Multispectral UV Analysis", CALIOPE Program $4^{\text {th }}$ Interim Technical Review Proceedings, Vol. 1, (1997).

18) J.S. Wagner, M.W. Trahan, W.E. Nelson, G.C. Tisone, B.L. Preppernau, "How intelligent chemical recognition benefits from multivariate analysis and genetic optimization", Computers in Physics 10, 114-118 (1995).

19) R.A. Gieray, P.T.A. Reilly, M. Yang, W.B. Whitten, J.M. Ramsey, "Real-time detection of individual airborne bacteria", Journal of Microbiological Methods 29, 191-199 (1997).

20) E.P. Parker, S.E. Rosenthal, M.W. Trahan, J.S. Wagner, W.B. Whitten, R.A. Gieray, P.T.A. Reilly, A. Lazar, and J.M. Ramsey, "Real-Time Analysis Of Individual Airborne Microparticles Using Laser Ablation Mass Spectroscopy And Genetically Traimed Neural Networks", Journal of Process Analytical Chemistry, accepted for publication. 


\section{Figure Captions}

Figure 1: Typical MPA results for single component positive ion unknowns.

A) Bacillus globigii spores.

B). Dactylis glomerata pollen.

C) NIST 8407 River Sediment particles

Figure 2: MPA results for a computer synthesized mixture of the negative ion spectra of Azotobacter vinelandii, Ambrosia trifida, and NIST 1645 River Sediment.
A) MPA Results
B) Mixture Component Spectrum for Azotobacter vinelandii bacteria.
C) Mixture Component Spectrum for Ambrosia trifida pollen.
D) Mixture Component Spectrum for NIST 1645 River Sediment particles.

Figure 3: 3D barplot of the common features (interferences) between species in MPA results. Each species is designated with an S, so the row labeled S1 corresponds to Avin, S2 to Bsubt, etc. S1-S6 are bacteria, S7-S12 are pollens, and S13-S18 are particulate samples.
A) Set 1 Negative ion results. This plot is rotated by 90 degrees to show the lack of common features between the pollen samples and all other samples.
B) Set 2 Negative ion results. This plot is also rotated by 90 degrees. Set 2 contains the is only common feature between a pollen (Dactylis glomerata) and any other sample - the bacteria Bacillus subtilis.
C) Set 1 Positive ion results.
D) Set 2 Positive ion results.

Figure 4: MPA results for a computer synthesized mixture of the negative ion spectra of three NIST particulate samples: NIST 8407 River Sediment, NIST 2710 Montana Soil, and NIST Peruvian Soil.
A) MPA Results
B) Mixture Component.Spectrum for NIST 8407 River Sediment particles.
C) Mixture Component Spectrum for NIST 2710 Montana Soil particles.
D) Mixture Component Spectrum for NIST Peruvian Soil particles. 

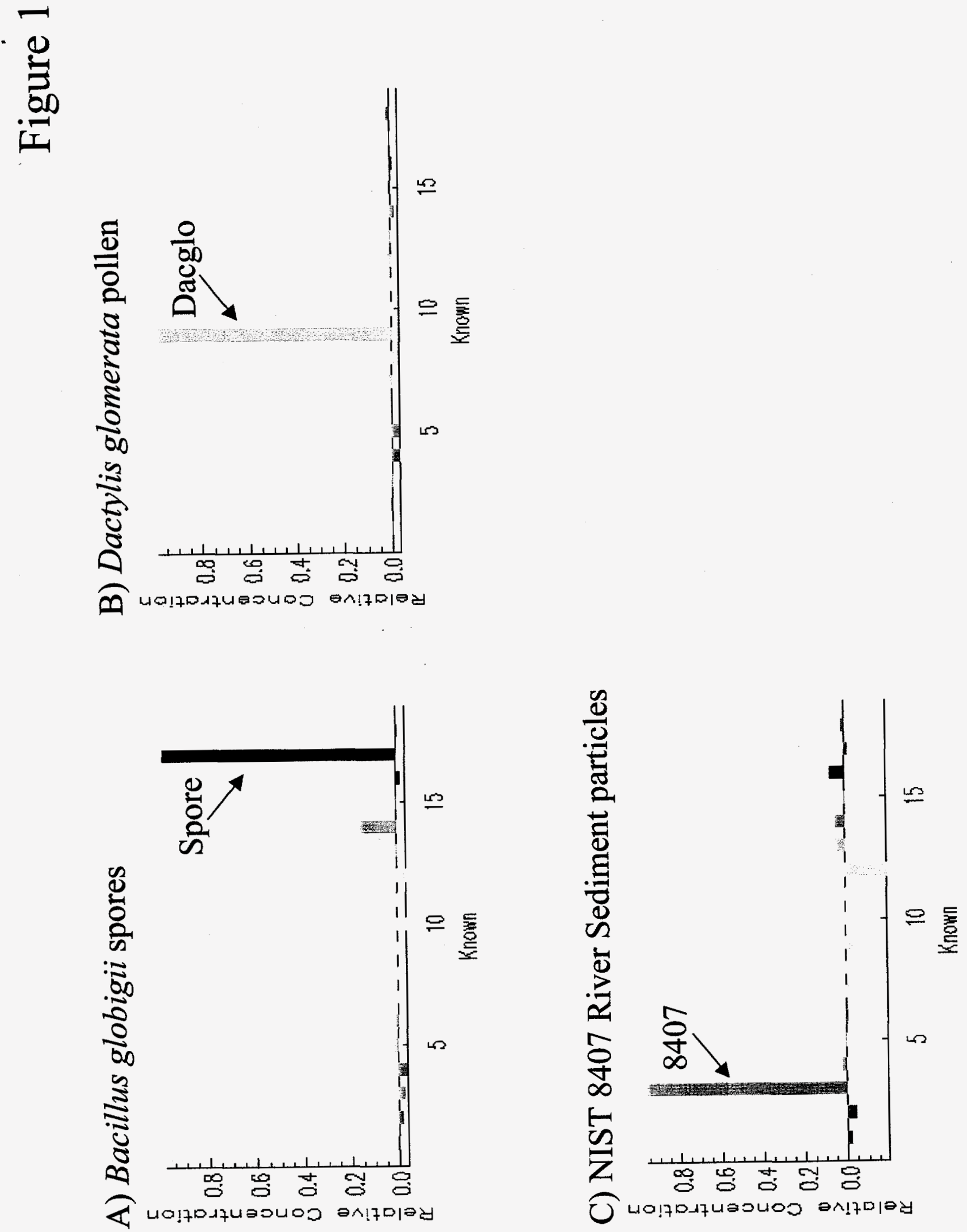

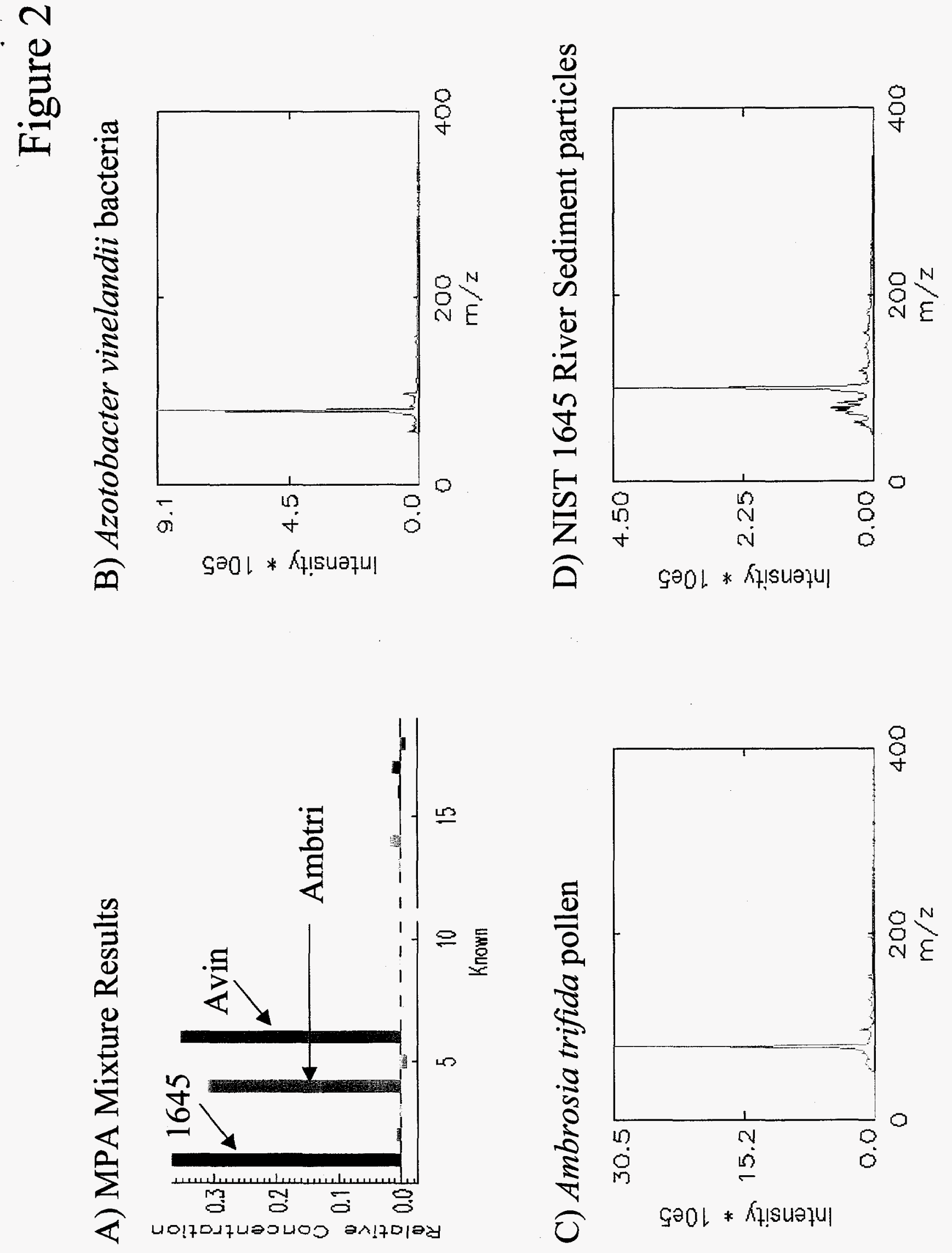

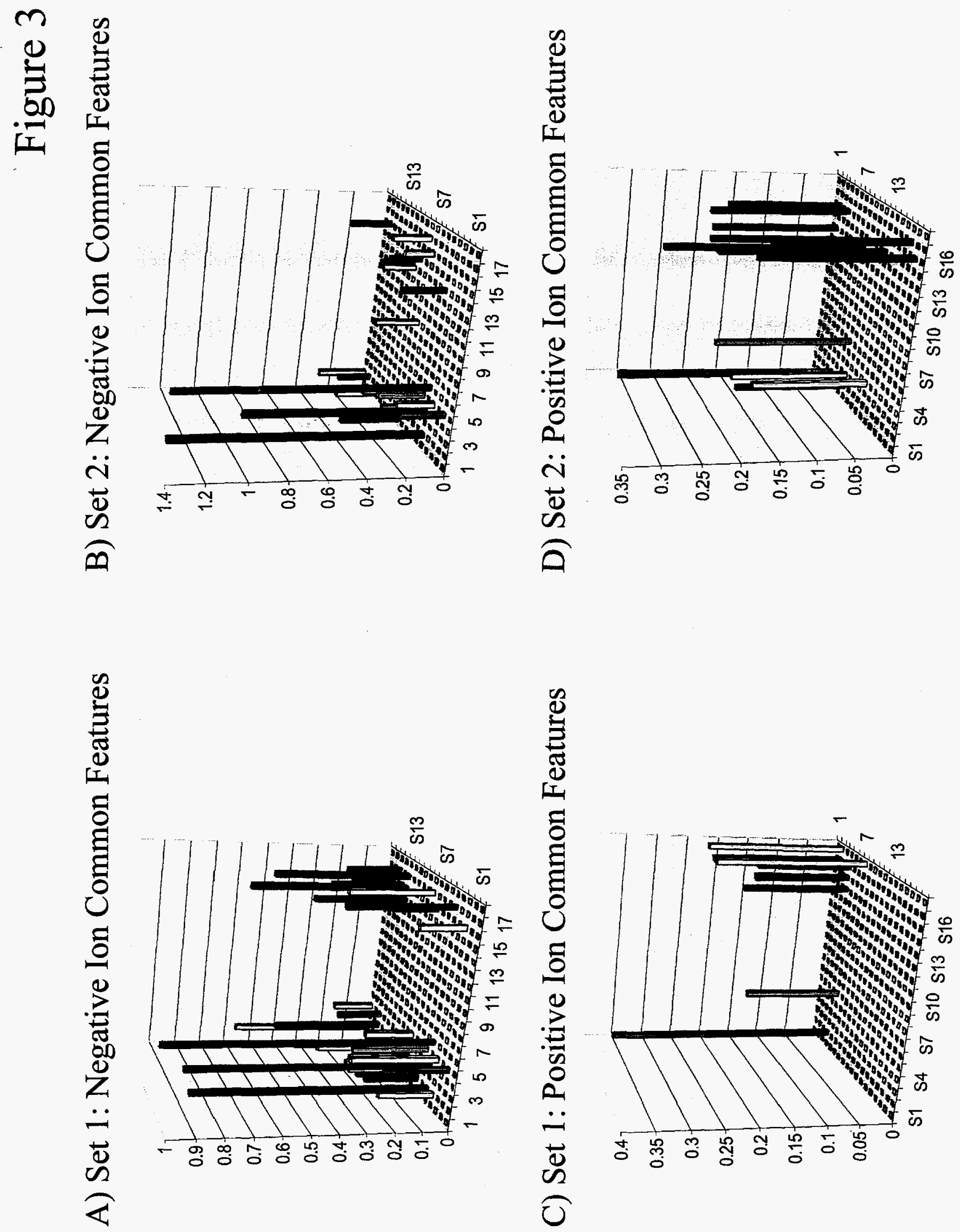

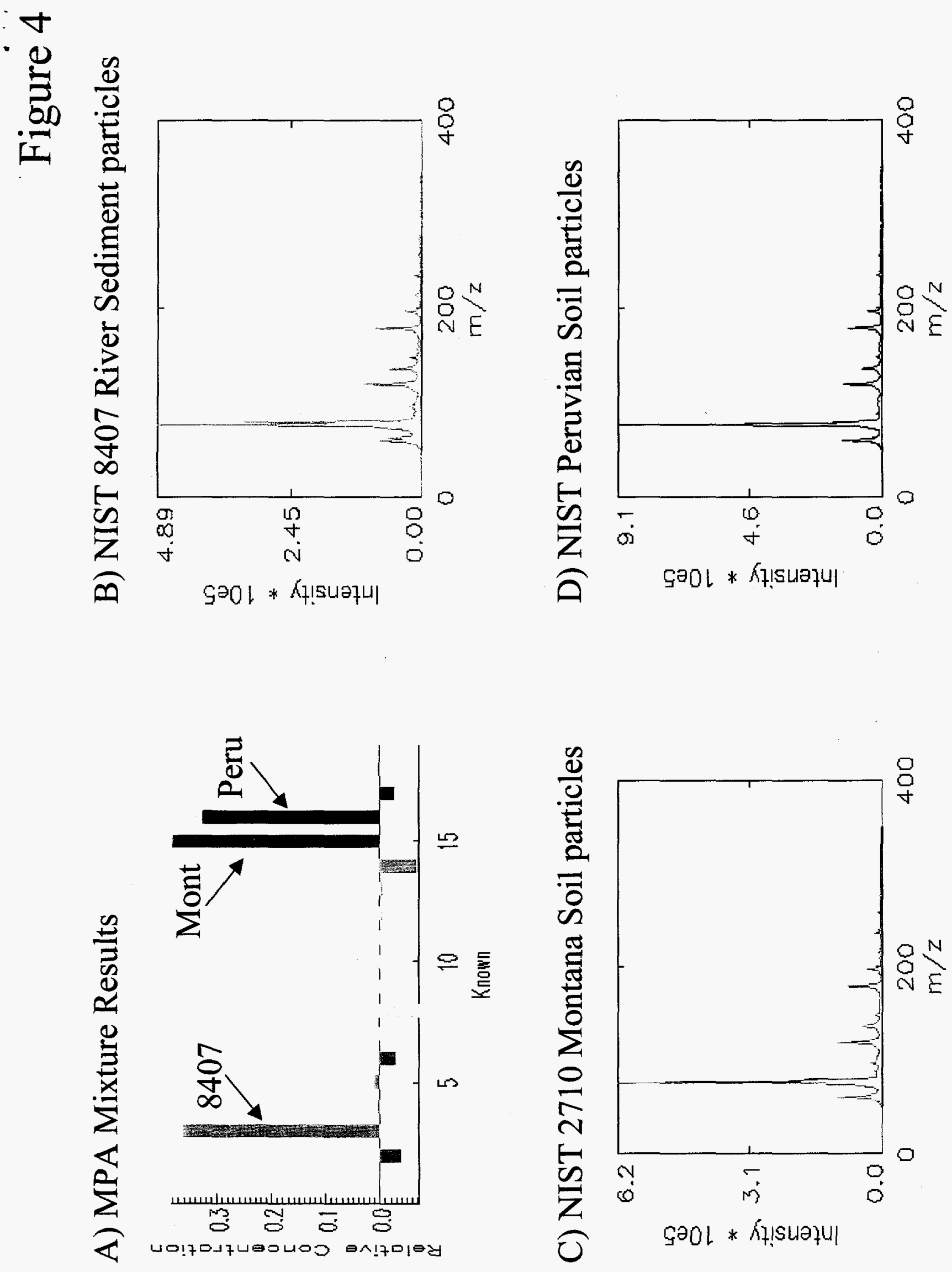